\title{
INTERNAL STRUCTURE AND COLOR OF THE NATURAL PLASTICALLY DEFORMED DIAMONDS FROM THE INTERNATSIONALNAYA KIMBERLITE PIPE (YAKUTIA)
}

\author{
E. N. Fedorova, A.M. Logvinova*, R.I. Mashkovtsev, N.V. Sobolev \\ VS Sobolev Institute of Geology and Mineralogy, Siberian Branch of Russian Academy of Sciences, Novosibirsk, Russia, \\ e-mail:logv@igm.nsc.ru
}

\section{INTRODUCTION}

The abundance of colored, plastically deformed diamonds in different kimberlite and lamproite pipes widely varies and is one of characteristics of a particular deposit. Brown and pink diamonds from the Argyle deposit in Australia (King et al., 2002), rare violet diamonds from the kimberlites of South Africa (Raal, 1958) are known. Diamonds with the color range from pink to purple occur in Mirny kimberlite field (the Internatsionalnaya and Dachnaya pipes, Yakutia) (Titkov et al., 2008). The origin of brown, pink, rare violet or purple color of diamonds is still under discussion (Gaillou et al, 2010). According to theoretical work (Hounsome et al., 2006) and transmission electron microscopy (Fisher, 2009) the brown color of diamonds can be caused by vacancy clusters in $\{111\}$ planes, which are form at during plastic deformation. It is theoretically calculated (Hounsome et al., 2006) that the extended defects as vacancy disks lead to monotonically increasing absorption in the range from 1 to $5.5 \mathrm{eV}$ (1240$225 \mathrm{~nm}$ ). Brown diamonds are known to have a series of absorption bands in the IR range from 4000 to $7000 \mathrm{~cm}^{-1}$ (Massi et al., 2005). "Amber centers" were observed in brown and brown with red or yellow hue diamonds (Reinitz et al., 2000). Large clusters of vacancies dissociate during HPHT treatment and brown color and "amber centers" disappear (Reinitz et al., 2000). The study of pink diamonds of Ia type has shown that color is distributed in the parallel lamellae oriented along the octahedral planes $\{111\}$ named "pink graining" (King et al., 2002). The optical absorption band with a maximum at $550 \mathrm{~nm}$, which is responsible for the pink color, is said to be related to plastic deformation of the diamond crystalline lattice, but the defect model has not been established (Gaillou et al, 2010). The aim of the present investigation is to study colored, plastically deformed diamonds from the Internatsionalnaya pipe (Yakutia), to determine the relations between the deformation level and color that is of interest not only for diamond genesis, but also for understanding the physics of optical absorption leading to the appearance of diamond color.

\section{SAMPLES AND EXPERIMENTAL TECHNIQUES}

45 diamond crystals from the Internatsionalnaya kimberlite pipe have been studied by optical spectroscopy and synchrotron Laue-SR method: 35 colored diamonds of brown and gray (group I), gray smoky with purplish pink hue (group II), light purplish pink with gray hue (group III), light purplish pink (group IV) color and 10 colorless diamonds for comparison. The crystal dimensions were about 1-2 mm. Colored diamond crystals were octahedral fragments or octahedra with different plastic deformations, as confirmed by microscopic examination. The surface of some samples was corrugated, while others demonstrated parallel striation, which reflected plastic deformation bands. All crystals demonstrated characteristic anomalous birefringence pattern in polarized light. X-ray synchrotron radiation (Laue-SR method) has been used to study the inner structure of plastically deformed crystals. It allows quick and effective study of imperfect crystals and determination of deformation degree (Rylov et al., 2001). Laue patterns have been obtained in the Institute of Nuclear Physics, Novosibirsk using VEPP-3 synchrotron radiation source with X-ray wavelength in the range from 0.5 to $5 \AA$. Diamond is almost transparent in this wavelength range. High intensity in the wide wavelength range and small beam divergence make it possible to obtain single step diffraction images of strongly deformed crystals, in this case diffraction images of the crystal or its fragment are topograms similar to the traditional X-ray topograms. Contrary to the traditional X-ray topograms, Laue-SR diffraction image doesn't disappear even if large disorientation of crystal blocks or other incoherent violations of the crystal lattice take place. Optical absorption spectra in the wavelength range from 300 to 900 $\mathrm{nm}$ were recorded using a Specord M40 spectrophotometer. 


\section{$10^{\text {th }}$ International Kimberlite Conference, Bangalore - 2012}

The absorption coefficient is expressedin $\mathrm{cm}^{-1}$ with regard to the thickness of the sample. Infrared (IR) spectra were recorded on a Bruker Vertex 70 FTIR spectrometer equipped with a Hyperion 2000 microscope with aperture value of $50 \mu \mathrm{m}$ in the frequency range from 500 to 5000 $\mathrm{cm}^{-1}$ with resolution of $1 \mathrm{~cm}^{-1}$. Relative nitrogen content in A-, B-centers was determined according to the absorption coefficients of the corresponding systems in IR-spectra by the standard procedure (Boyd et al., 1995).

\section{RESULTS AND DISCUSSION}

\section{Laue-SR method.}

The characteristics of plastically deformed diamonds studied by Laue-SR method are presented in the Table 1. The density of dislocations increases up to $10^{5}-10^{12} \mathrm{~cm}^{-2}$ and different defects form owing to plastic deformation with consequent strong changes of the structure of the

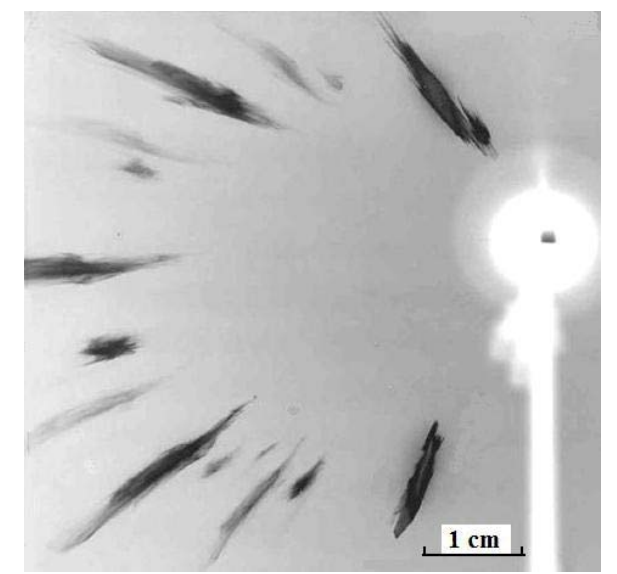

Fig. 1. The lauegram of the strongly deformed gray diamond (sample In22). Veiled-like Laue spots elongated in radial direction.

networks of crystal atoms. The increase in the number of dislocations can cause local zones with deformation of the crystal lattice. In this case Laue-spots extend in the radial direction and continuously blacken (Fig. 1). This phenomenon is known as asterism of Laue spots (Fridel, 1964). The size of Laue spot is several times greater than
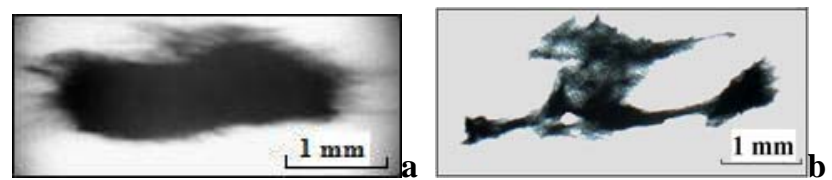

Fig. 2. X-ray Laue-SR topograms shows the different degree of deformation of brown and gray diamonds (I and II groups): a-srong deformation of brown diamond (sample In-10), b-irregular reorientation of individual local zones of the crystalline lattice leads to splitting of the Laue spots of gray diamond (sample In-11).
Table 1. Characteristics of plastically deformed diamonds from Internatsionalnaya pipe (Yakutia)

\begin{tabular}{|c|c|c|c|c|c|c|c|}
\hline \multirow{4}{*}{ Group } & \multirow{4}{*}{$\begin{array}{c}\text { Sample } \\
\text { In- }\end{array}$} & \multicolumn{2}{|c|}{ Laue-SR } & \multicolumn{4}{|c|}{ Spectroscopy, $\alpha \mathrm{cm}^{-1}$} \\
\hline & & & & \multirow{2}{*}{\multicolumn{2}{|c|}{$\begin{array}{c}\text { UV-Vis } \\
\mathrm{nm}\end{array}$}} & \multirow{2}{*}{\multicolumn{2}{|c|}{$\frac{\text { IR }}{\mathrm{cm}^{-1}}$}} \\
\hline & & & & & & & \\
\hline & & $\mathrm{PD}$ & $\mathrm{P}-\mathrm{G}$ & 480 & 550 & 4065 & 4170 \\
\hline \multirow{4}{*}{ I } & 12 & + & - & & & 0.9 & 0.8 \\
\hline & 10 & + & - & & & 0.6 & 0.6 \\
\hline & 21 & + & - & & & 0.6 & 0.5 \\
\hline & 25 & + & - & & & 0.7 & 0.5 \\
\hline \multirow{4}{*}{ II } & 11 & + & - & 1.2 & 1.4 & 0 & 0.2 \\
\hline & 9 & + & - & - & 1.2 & 0.7 & $\mathrm{sh}$ \\
\hline & 22 & + & - & 1.5 & 2.3 & 0.7 & sh \\
\hline & 16 & + & - & 0.6 & 0.9 & 0.1 & sh \\
\hline \multirow{4}{*}{ III } & 14 & + & + & 0.6 & 1 & 0.4 & 0.3 \\
\hline & 18 & + & + & 0.4 & 0.8 & 0.2 & 0.1 \\
\hline & 36 & + & + & - & 1.8 & 0.1 & $\mathrm{sh}$ \\
\hline & 37 & & & 1.4 & 1.9 & 0.4 & sh \\
\hline \multirow{4}{*}{ IV } & 2 & + & + & - & 3.2 & - & - \\
\hline & 8 & + & + & - & 3.5 & - & - \\
\hline & 26 & + & + & - & 3 & - & - \\
\hline & 27 & + & + & - & 2.3 & - & - \\
\hline
\end{tabular}

Note: PD - plastic deformation; PG - polygonization; $\alpha$ - absorption coefficient; sh - shoulder; $(+)$ - well expressed phenomenon; (-) - no phenomenon observed.

the real crystal size in this case the topograms represent a complete loss of crystal projection (Fig. 2). The higher is the degree of crystal deformation the more elongated and distorted are the Laue spots. In the brown and grey diamonds of I and II groups (Table 1, Fig. 1) the strong asterism of diffraction contrast on the topograms is observed and it is caused by the local bending of the slip planes and reorientation of individual sections with respect to each other in the deformed crystal. In the crystals with the high deformation level it is impossible to reveal different deformation levels: slip, climb, deformation bands, kinking, fragmentation, and Laue spots become completely darkened (Fig. 2a). Reoriented sections can be regularly arranged relative to the basic part of the crystal contributing to the formation of mechanical twins. Irregular reorientation of individual local zones of the crystalline lattice can occur during plastic deformation along with mechanical twinning, in this case Laue spot is split to several reflexes mutually disoriented at small angles (Fig. 2b). It has been found (Mokievsky et al., 1962) that splitting of the Laue spot directly depends on the reorientation angles of microtwin layers, which diverge from the basic part of the crystal from $2^{\circ}$ to $8^{\circ}$. Splitting corresponds to the lattice reorientation 


\section{0 ${ }^{\text {th }}$ International Kimberlite Conference, Bangalore - 2012}

through the angle of about $4^{\circ}$ for the diamond In-11 (group II) (Fig. 2b). These irregularly reoriented microtwin layers are kink bands (Mokievsky et al., 1962). Kink bands are a complex plastic deformation by slip at the inhomogeneous slip distribution in the crystal which causes disorientation of its individual local zones of the crystalline lattice relative to the host crystal (Klassen-Neklyudova, 1960). Numerous point defects formed during plastic deformation are particularly thermodynamically unstable and annealed due to atoms diffusion (Collins, 2001). However the properties related to dislocations can be restored at higher annealing temperature than the temperature of plastic deformation, for example, the temperature, which can be reached in laboratory conditions during the annealing of brown diamonds or natural long annealing (Fisher et al., 2009). During annealing the dislocations move so that elastic energy decreases, the dislocations are redistributed forming dislocation walls of the same sign, which separate more perfect but disoriented relative to each other polygonization grains (Fridel, 1964). Laue spots of crystals, which underwent polygonization, have nearly parallel striation, which reflects the distribution of dislocations in the crystal (Urusovskaya and Orlov, 1964). According to Laue-SR data brown and gray diamonds (I, II groups) have not been subjected to natural annealing and do not show polygonization (Table 1). They have been probably deformed immediately before their export to the Earth's surface by kimberlite rocks. In the conditions of abrupt temperature decrease (as compared to the temperature of plastic deformation) and pressure drop, when the diffusion processes are slowed down or stop completely the lattice distortions during prior deformation are remained, in this case residual thermal and dynamic elastic stresses are still retained (Yushkin, 1971). Veiled tails and needles beyond the main diffraction spots, observed for the diamonds of I, II, groups (Fig. 2), characterize the presence of elastic residual stresses of crystalline lattice. According to LaueSR data diamonds of III and IV groups underwent polygonization (Table 1, Fig. 3). Laue spots of purplish
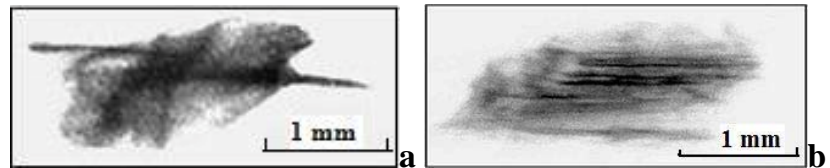

Fig. 3. Laue spots of light purplish pink with gray hue (group III) and light purplish pink (group IV): a-deformation leads to the veiled tails extending beyond the main diffraction spot, inside the main diffraction spot there are bands typical of the polygonization (sample In-18); b-slip systems deformation bands extending throughout the crystal (sample In-27).

pink with brown or gray hue diamonds (III group) have quasi-linear striation as a result of polygonization, but the veils extending beyond the main diffraction spots characterize the presence of residual elastic stresses of crystalline lattice (Fig. 3a). Laue spots for all light purplish pink diamonds (group IV) studied by Laue-SR methodshow quasi-linear striation which reflects the distribution of the dislocations in the crystals. Figure $3 \mathrm{~b}$ demonstrates Laue spot of purplish pink sample In-27 with colored bands on (111) plane.

\section{UV-Vis spectroscopy.}

A continuum of absorption rising progressively from the near IR to UV region of the spectrum has been observed for brown, gray diamonds and purplish pink diamonds with gray or brown hue and that is different from the optical spectrum of purplish-pink diamonds of IV group and nondeformed diamonds of good optical quality (Fig. 4). For the non-deformed diamond the absorption edge is conditioned by the presence of nitrogen in A-form and begins from

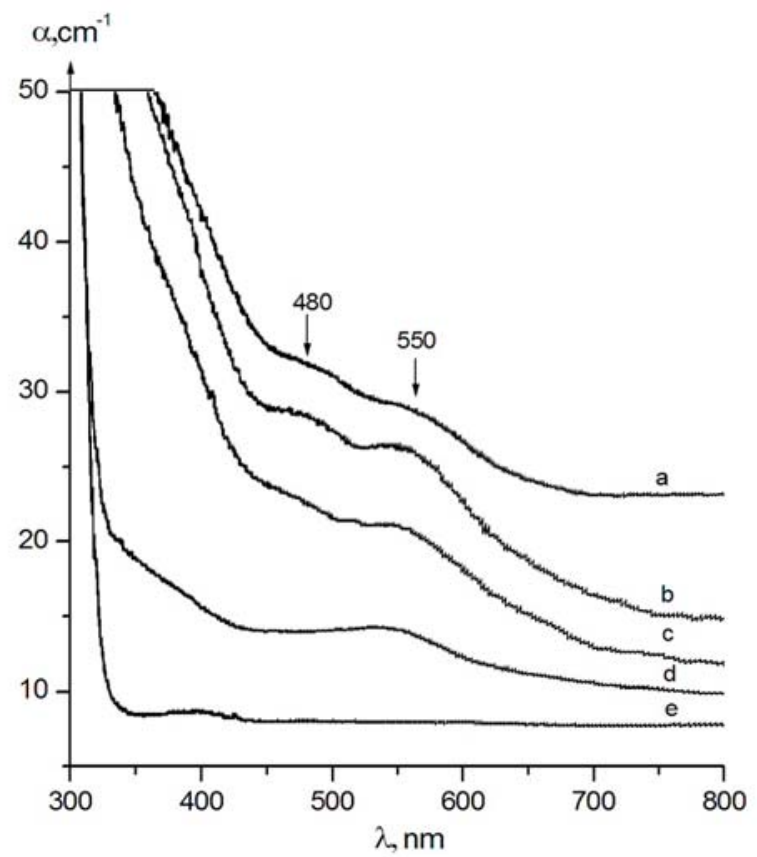

Fig. 4. Optical absorption spectra of plastically deformed diamonds (curves $\mathrm{a}-\mathrm{d}$ ) and strainless diamond (curve e): a-sample In-10 (group I), b-sample In-22 (group II), c-sample In-13 (grop III), d-sample In-2 (group IV), esample In-52 (gem-quality diamond).

$\sim 320 \mathrm{~nm}$ (Fig. 4e). For purplish-pink diamonds the band at $550 \mathrm{~nm}$ along with the absorption increase from the wave length below $\sim 400 \mathrm{~nm}$ is observed (Fig. 4d). Two bands with absorption maxima at 480 and $550 \mathrm{~nm}$ have been registered for gray-smoky, brown with purplish-pink hue (group II) and purplish-pink with brown or gray hue diamonds (group III) against the background of intense continuous absorption (Fig. 4 b,c). Purplish-pink diamonds with gray hue have less intense continuous absorption background in UV-Vis spectral region and more expressed absorption band at $550 \mathrm{~nm}$ as compared to the diamonds of group I (Fig. 4c). Purplish pink diamonds of group IV are characterized by the absorption band at $550 \mathrm{~nm}$ (Fig. 4d, 


\section{0 ${ }^{\text {th }}$ International Kimberlite Conference, Bangalore - 2012}

Table 1). It should be noted that some crystals of I group have a broad absorption band in the form of a shoulder at $550 \mathrm{~nm}$ (Table 1, Fig. 4a). As regard, the broad absorption band in the visible spectral region with maximum at $550 \mathrm{~nm}$ is responsible for the pink color diamonds.

\section{FTIR spectroscopy.}

According to IR spectroscopic data both plastically deformed and non-deformed good optical quality diamonds under study are referred to IaA type by the nitrogen impurities content, i.e. contain nitrogen defects A, B, with $\mathrm{A}>>\mathrm{B}$. The IR spectrum of I-III diamonds is characterized by two broad absorption bands, known in literature as "amber centers" (Massi et al., 2005) with maximum at 4065 $\mathrm{cm}^{-1}$ and $4170 \mathrm{~cm}^{-1}$ (inset in Fig. 5). Purplish-pink and pink diamonds (group IV) have no absorption bands related to "amber centers" (Fig. 5d). The absence of "amber centers" in the IR spectra of pink natural diamonds has been shown

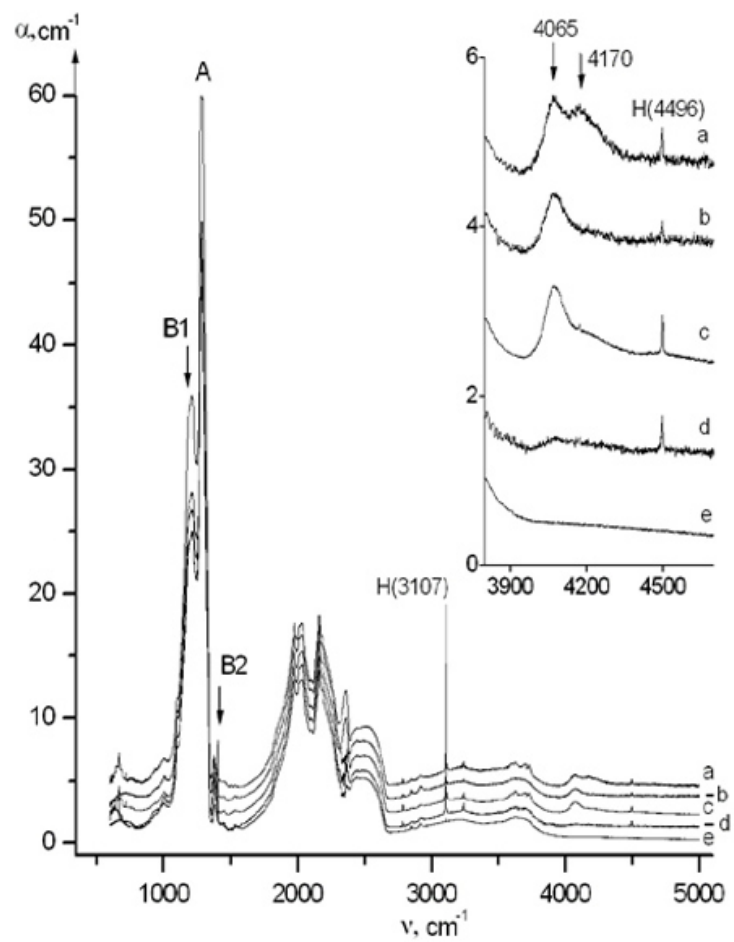

Fig. 5. IR spectra of plastically deformed diamonds (curves a $-\mathrm{d}$ ) and strainless diamond (curve e): a-sample In-10 (group I), b-sample In-22 (grou II), c-sample In-13 (group III), d-sample In-2 (group IV), e-sample In-52 (gem-quality diamond). Inset: the "amber centers" in low energy part of the spectra.

by De Weerdt and Van Royen (2001). It is shown that "amber centers" are annealed during HPHT treatment just like a brown component (Reinitz et al., 2000). There is no correlation between the total nitrogen content and the intensity of the "amber centers" for the collection of plastically deformed diamonds studied in this work. According to our data the intensity of the "amber centers" absorption bands depends on the deformation level. Diamonds with strongly deformed crystalline lattice due to plastic deformation have more intense "amber centers", in this case both absorption bands at 4065 and $4170 \mathrm{~cm}^{-1}$ are intense for brown and gray diamonds (Table 1, Fig. 5a). More intense absorption band at $4065 \mathrm{~cm}^{-1}$ and $4175 \mathrm{~cm}^{-1}$ is registered mostly like a shoulder for diamonds of II and III groups (Fig. 5b,c).

\section{Plastic deformation of natural diamonds.}

It is widely believed that diamond plastic deformation can occur in nature under the effect of dynamic processes followed by the disintegration of the deep-seated rocks and transportation of diamonds to the Earth's surface by kimberlite and lamproite magmas. In addition, the mantle itself may be an adverse environment, in which diamond plastic deformation may occur and diamonds can suffer plastic deformation not only at the final stage of their history during the transportation by kimberlite and lamproite magmas but at the early stages as well (Fischer, 2009). It is known that the centers responsible for the brown color of diamonds are unstable thermally and annealed at HPHT treatments $\left(\mathrm{T}>1800^{\circ} \mathrm{C}\right.$ and $\left.6 \mathrm{GPa}\right)$ that prevents the brown center's formation in the extreme conditions of the Earth's upper mantle (Collins et al, 2000). On the other hand, the defects responsible for pink color are more stable to HPHT treatments and would be expected to survive in the mantle conditions for a long time (Collins et al, 2000). Then it is possible to explain more rare pink color as compared to the brown one because diamond deformation in the mantle is a rare event or such deep-seated diamonds are rarely carried to the Earth's surface (Gaillou et al., 2010). The formation of dislocation walls, known as "graining", may be formed both by polygonization as a result of annealing after drastic deformation (static polygonization) and during plastic deformation, when sliding along just one system of parallel planes take place (dynamic polygonization) (Fridel, 1964). Relatively low temperature and short duration of stress application are the main contributions factors to dynamic polygonization of the high symmetry crystals such as diamond (Fridel, 1964; Mineeva et al., 2007). It is unlikely that purplish-pink diamonds of the investigated collection have experienced prolonged annealing resulted in their polygonization. The degree of nitrogen aggregation (percentage of nitrogen in $\mathrm{B}$ form) is much the same $(10-30 \%$ B) both for plastically deformed diamond crystals and non-deformed diamonds. Low degree of nitrogen aggregation is typical for the Internatsionalnaya pipe (Bogush and Vasilyev, 2008). In the event of prolonged annealing in nature, which is essential for dislocations rearrangement and formation of polygonization grains in plastically deformed crystals (Fisher, 2009), probably, there would have been higher 


\section{0 ${ }^{\text {th }}$ International Kimberlite Conference, Bangalore - 2012}

nitrogen aggregation. On this basis it is believed that dynamic polygonization of diamonds during transportation from mantle to the Earth's surface but not static polygonization during the prolonged annealing in nature after plastic deformation in the mantle has occurred for light purplish-pink diamonds of III and IV groups studied in the work. It should be noted that the mechanism of plastic deformation of diamonds in nature is rather complicated and defined not only by temperature and applied stress but the inherent properties of the diamond crystal (initial growth dislocations, point defects, inclusions), mechanical properties and degree of homogeneity of the medium in which the crystal is deformed (Shiryaev et al., 2007).

\section{CONCLUSIONS}

According to Laue-SR data the brown and gray (I group), smoky-gray with purplish-pink hue diamonds (II group) have not been subjected to annealing after deformation: they do not show polygonization, Laue spots demonstrate strong asterism and fragmentation, indicating a high deformation level of the diamonds of I and II groups. This deformation level is followed by the extended defects in the form of vacancy clusters, which cause a continuous absorption throughout the visible region of the spectrum responsible for the brown color of diamonds. The "amber centers" in IR region with the absorption at 4065 and 4170 $\mathrm{cm}^{-1}$ are typical of these diamonds.

The inner structure of purplish-pink with gray hue diamond crystals (group III) is characterized by the deformation lamellae with negligible local discrete disorientations in some directions. Broad absorption bands with maxima at 480 and $550 \mathrm{~nm}$ appear on the background of complete absorption in UV-Vis area with weaker absorption intensity as compared to the diamonds of I and II groups. "Amber centers" of lower intensity than in brown and gray diamonds of the studied collection are manifested in the IR region.

The inner structure of the purplish-pink diamonds (group IV) is characterized by polygonization lamellae along the octahedral planes. The lack of asterism of Laue spots is indicative of the absence of disoriented regions in the sliding traces. No "amber centers" have been found in the IR region. These crystals are characterized by the intense absorption band with maximum at $550 \mathrm{~nm}$ related to the pink color. In contrast to non-deformed diamonds the absorption is observed at $400 \mathrm{~nm}$ instead of the typical band at $320 \mathrm{~nm}$ for IaA type diamonds. This absorption is, probably, responsible for the purplish hue of the studied diamonds.

\section{References}

Bogush, I.N., Vasilyev, T.A. (2008) Features of diamond from deposits of Siberia revealed by FTIR $9^{\text {th }}$ International Kimbrlite Conference. Extended Abstract, No. 9IKC-A-00215.
Boyd, S.R., Kiflawi, I., Woods, G.S. (1995) Infrared absorption by B nitrogen aggregate in diamond. Phil. Mag. v. B 72, 3, pp. 351-361.

Collins A.T., Kanda H., Kitawaki H. (2000) Colour changes produced in natural brown diamonds by high pressure, high- temperature treatment. Diamond and related materials v. 9, pp. 113-122.

Collins, A.T. (2001) The colour of diamond and how it may be changed. J. Gemm. v. 27, No 6, pp. 341-359.

De Weerdt, F., Van Royen, J. (2001) Defects in coloured natural diamonds. Diamond and related materials v. 10, pp. 474-479.

Fisher, D. (2009) Brown diamonds and high pressure high temperature treatment. Lithos, v. 112S, pp. 619-624.

Fisher D., Sibley, S.L., Kelly, C.J. (2009) Brown colour in natural diamond and interaction between the brown related and other colour-inducing defects J. Phys.: Condens. Matter, v. 21, 364213 (10pp).

Friedel G (1964) Dislocations. Pergamon Press, London-New York.

Fritsch E., Collins A.T., Hainschwang T., Notari F. (2005) The "amber centers" find their relation to the brown colour in diamond. Diamond and related materials v. 14, pp.1623-1629.

Gaillou E., Post J.E., Basin N.D. et.al. (2010) Spectroscopic and microscopic characterizations of color lamellae in natural pink diamonds. Diamond and related materials, v. 19, pp. 1207-1220.

Hounsome L.S. and Jones R., Martineau P.M. and Fisher D., Shaw M.J. and P.R. Briddon, Oberg S. (2006) Origin of brown coloration in diamond. Physical Review v. B73, pp. 125203.

King, J.M., Shigley, J.E., Guhin, S.S., Gelb, T.H., Hall, M. (2002) Characterization and grading of natural-color pink diamonds. Gems \& Gemol v. 38, pp. 128-147.

Klassen-Nekludova M.V. (1960) Mechanical twinning of crystals Izd. AN SSSR, M., 163 pp.

Fritsch E., Collins A.T., Hainschwang T., Notari F. (2005) The "amber centers" find their relation to the brown colour in diamond. Diamond and related materials v. 14, pp.1623-1629.

Reinitz, I.M., Buerki, P.R., Shigley, J.E., McClure, S.F., Moses, T.M., (2000) Identification of HPHT-reated Yellow to Green Diamonds. Gems \& Gemol v. 34, pp. 128-137.

Massi L., Fritsch E., Collins A.T., Hainschwang T., Notari F. (2005) The "amber centers" find their relation to the brown colour in diamond. Diamond and related materials v. 14, pp.1623-1629.

Mineeva, R.M., Speransky, A.V., Titkov, S.V., Zudin, N.G. (2007) The ordered creation of paramagnetic defects at plastic deformation of natural diamonds. Phys. Chem. Minerals v. 34, No 2, pp. 53-58.

Mokievsky,V.P., Titova, V.M., Bartoshinsky Z.V. (1962) Manifistation of plastic deformation in diamonds and some problems related to crystal plasticity. Zap. VMO, v. 91, No 4, pp. 381-393.

Raal F.A., (1958) A new absorption bands in diamond and its likely cause. Proceedings of Physical Society of London v. 71, pp. 846-847.

Reinitz, I.M., Buerki, P.R., Shigley, J.E., McClure, S.F., Moses, T.M., (2000) Identification of HPHT-reated Yellow to Green Diamonds. Gems \& Gemol v. 34, pp. 128-137.

Rylov, G.M., Yefimova E.S., Sobolev N.V., Kulipanov G.N., Kondratyev V.I., Tolochko B.P., Sharafutdinov M.R. (2001) Study of imperfect natural diamonds with the application of the X-ray synchrotron radiation (the "Laue-SR" method). Nucl. Instr. and Meth., v. A 470, Is. 1-2, pp. 182-188.

Shiryaev, A.A., Frost, D.J., Langehorst, F. (2007) Impurity diffusion and microstructure in diamond deformed at high pressures and temperatures. Diamond and related materials, v. 16, pp. 503-511.

Titkov, S.V., Shigley, J.E., Breeding, Ch.M., Mineeva, R.M., Zudin, N.G., Sergeev A.M. (2008) Natural-Color Purple Diamonds from Siberia. Gems \& Gemol. v. 44, Is. 1, pp. 56-64.

Urusovskaya, A.A, Orlov, Yu.A. (1964) Character plastic deformation of diamond crystals. Dokl. AN SSSR, v. 154, No 5, pp. 1099-1102.

Yushkin, N.P. (1971) Mechanical properties of minerals. M. Nauka, 282 p. 
$10^{\text {th }}$ International Kimberlite Conference, Bangalore - 2012 